\title{
Effectiveness and Discussion of Ventilation Design with Automatic Revolving Window
}

\author{
Jing Yi Chang ${ }^{1 *}$, Yean Der Kuan², Chun Ching Lan ${ }^{2}$, Hsing Ju Li ${ }^{2}$, Yu Kun Hsu², Chih Yao Chen², En Ting Shen ${ }^{2}$, Chih \\ Yen Chen ${ }^{1}$ \\ ${ }^{1}$ Department of Marine Engineering, Taipei College of Maritime Technology, Taipei, Taiwan \\ ${ }^{2}$ Department of Refrigeration, Air-Conditioning and Energy Engineering, National Chi-Yi University of Technology, Taichung, Taiwan
}

\begin{abstract}
This paper aims to improve and discuss the effectiveness of automatic revolving window ventilation on human comfort, where the temperature sensor mounted indoors gives the signal to start the stepping motor of the revolving window. There is a controller for automatic regulation according to the difference between the preset temperature and indoor temperature, where the air flow of ventilating fan imports outside air to take excess heat away from the room, in order to reduce the indoor temperature. The revolving window opening angle is simulated and analyzed, and the impact of different air rates on the indoor temperature is analyzed. This system can regulate the indoor temperature to effectively reach the optimal human comfort temperature, and can reduce the frequency of using air conditioning, in order to attain the goals of energy saving, carbon reduction, and environmental protection.
\end{abstract}

\section{Introduction}

This study starts with "energy saving starts with everybody", and joins the modern trend of regulating the optimum thermal comfort environment. The thermal comfort environment means the physical factors of temperature, humidity, and air flow acting synthetically on the human body, and the human body is comforted when in the optimum combination state [1]. The temperature is the key to human comfort. The human body temperature is mostly kept at $37{ }^{\circ} \mathrm{C}$, and if the environmental conditions are favorable for evaporating sweat, the human skin surface is kept dry. Therefore, the regulation of body temperature is very important for health and comfort [2]. When human body surface skin is exposed to the external environment, the skin transfers heat to the external environment for temperature regulation. The higher the air velocity is, the faster the skin temperature falls, and the closer the skin temperature is to the air temperature. Therefore, in addition to air temperature difference, the air velocity is closely related to human comfort in a low temperature environment [3].

Modern people mostly live in confined spaces for $90 \%$ of their life; however, indoor comfort conditions are neglected, and the environmental quality directly influences human health, thus, indoor thermal comfort and air quality are major topics [4]. Taiwan has actively advocated building energy saving in recent years, and established the system of "nine major indices of green buildings", which is devoted to ecology, energy saving, waste reduction, and health [5]. This study uses an automatic temperature sensing revolving window and an exhaust fan to adjust the indoor air flow to carry hot air away, and improve indoor air quality. The air consists of multiple gases, in addition to vapor, it consists of $78.10 \%$ nitrogen, $20.93 \%$ oxygen, and $0.03 \% \mathrm{CO} 2$. It is obvious that oxygen accounts for a considerable proportion of the air. An excess of $\mathrm{CO} 2$ content in the space can cause risk to the human body by losing consciousness. Generally, the arrangement of air inlet/outlet shall avoid a short circulation flow path. This study uses a diagonal path, where the window and fan are separated at $90^{\circ}$, and imported fresh air is kept indoors moderately, in order that cool air can effectively flow to various corners, and exchange with hot air to eliminate human discomfort.

Energy saving must be started from the air conditioning, and the room temperature determines the operation of air conditioning. It is indicated that, the comfortable temperature is $27.17^{\circ} \mathrm{C}$ when the relative humidity is $60 \sim 70 \%$ and the air velocity is $0.2 \mathrm{~m} / \mathrm{s}$; the comfortable temperature is $28.30^{\circ} \mathrm{C}$ when the air velocity is $0.5 \mathrm{~m} / \mathrm{s}$. According to the relative humidity and the information of the energy label, "air conditioning power consumption can be reduced by $6 \%$ as the air conditioning temperature is increased by $1{ }^{\circ} \mathrm{C} "$. Outside air is imported for forced ventilation, which reduces the room temperature in advance, and the heat of indoor air is completely exchanged. In order to improve indoor air quality and human comfort, if the outside fresh air is imported by appropriate forced convection at ambient temperature without air conditioning to take indoor heat away and continuously improve the indoor air quality [6],

\footnotetext{
${ }^{\mathrm{a}}$ Corresponding author: author@e-mail.org
} 
the consumption of air conditioning can be reduced greatly for energy saving. The automatic system has become the present trend for improving life quality, which is also one of our goals, thus, the concept of automatic control is used in windows in order to meet humanistic demands while saving energy.

\section{Research Procedures}

This study discusses the overall operation of revolving windows and its effect on indoor ventilation. The temperature sensor, which is mainly a non-contact temperature sensor, detects the room temperature without contacting the test medium; the temperature is transmitted by thermal radiation or convection to the temperature sensor for temperature measurement, and the temperature data are transferred as signals to the control circuit for subsequent analysis and processing, in order to determine whether or not to adjust the room temperature, and the corrected signal is sent to the stepping motor.

As shown in Figure 1, the upper stepping motor drives the glass window to revolve, the angle is controlled according to the signal when the stepping motor is running, and the ball bearing under the window not only reduces the resistance to pivoting friction, but also reduces the noise resulted from the friction of the bearing surface, and thus, effectively prolongs the service life of the window. Finally, air is imported to reduce the room temperature, and improve the indoor air quality and human comfort. The temperature sensor again detects whether the room temperature has reached the preset temperature, then maintains control and adjustments. The aforesaid control path forms a cycle, as shown in Figure 2.

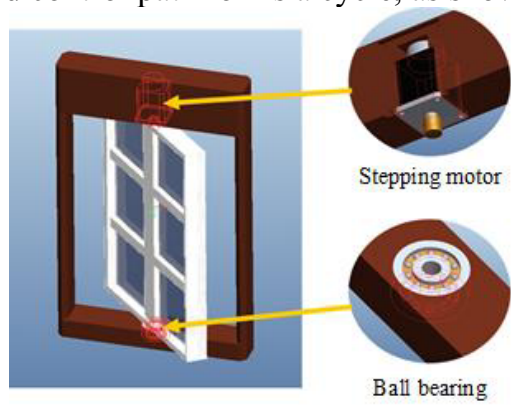

Figure 1. Schematic diagram of revolving window and assemblies

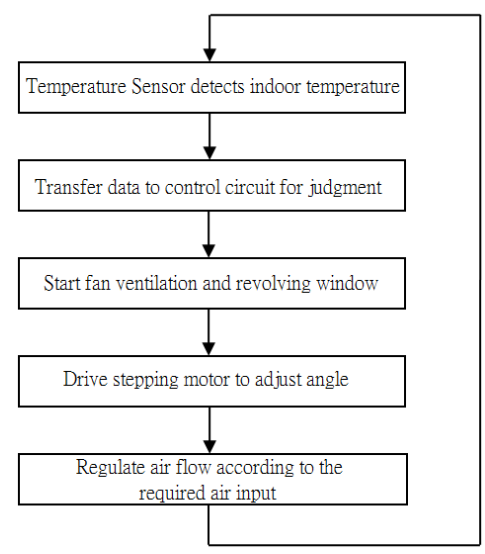

\subsection{Design of revolving window angle for air flow}

Forced ventilation is the power generated by ventilating machinery (fan, blower, exhaust fan), and contributes to the exchange and flow of indoor and outdoor air. Mechanical ventilation is applicable to an insufficient natural air rate or a room with harmful or combustible gas. It is characterized by stable air flow, and the air rate can be controlled as required.

The ventilating fan imports the outside air into the room, the indoor air is exhausted by the ventilating fan, a low pressure field is formed in the room, the indoor heat and human exhaled $\mathrm{CO} 2$ are carried away by the pressure difference, and the revolving window opening is adjusted by the automatic control system, where the angles are 30 , 60 , and $90^{\circ}$, as shown in Figure 3, and the rotation speed of the fan is controlled by a variable frequency for energy saving.
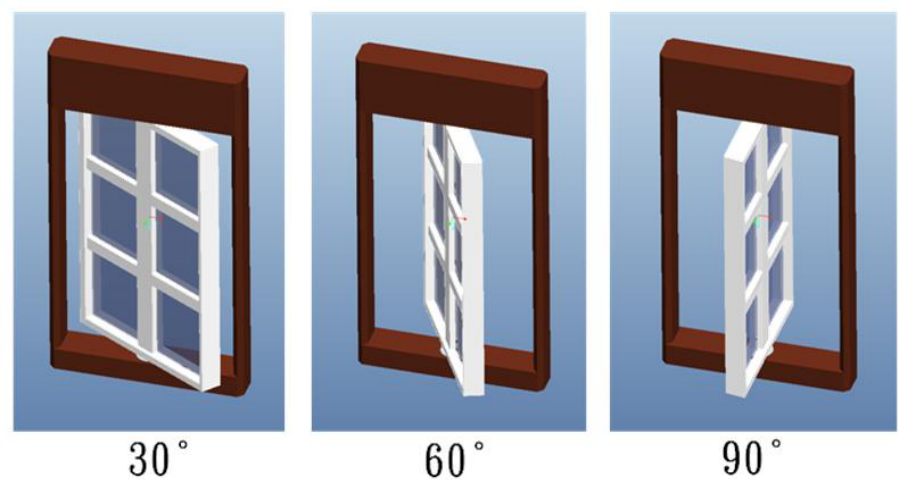

Figure 3. Revolving window rotation angle

\subsection{CFD software simulated fluid flow field analysis}

The Ansys Fluent software uses different discrete formats and numerical methods for different complex flows and physical phenomena, and uses computing speed, stability, and accuracy in a specific domain to solve the computational problem of complex flow in various domains. The ventilation system uses heat flow field analysis software to build model parameters in a computer, the model region is defined, the mesh is designed and divided, the model uses geometrical mesh to imitate the actual state, thus, simulating the actual fluid flow and heat transfer property. There are different area solutions in the software: structured grid computation, unstructured grid computation, fluid-solid coupling, viscous and elastic flow, mixing, and thermal control analysis. Different modules are calculated according to the simulation requirements, and the simulated data results are visualized to determine the ideal analysis, as shown in Figure 4.

Figure 2. System control flow 


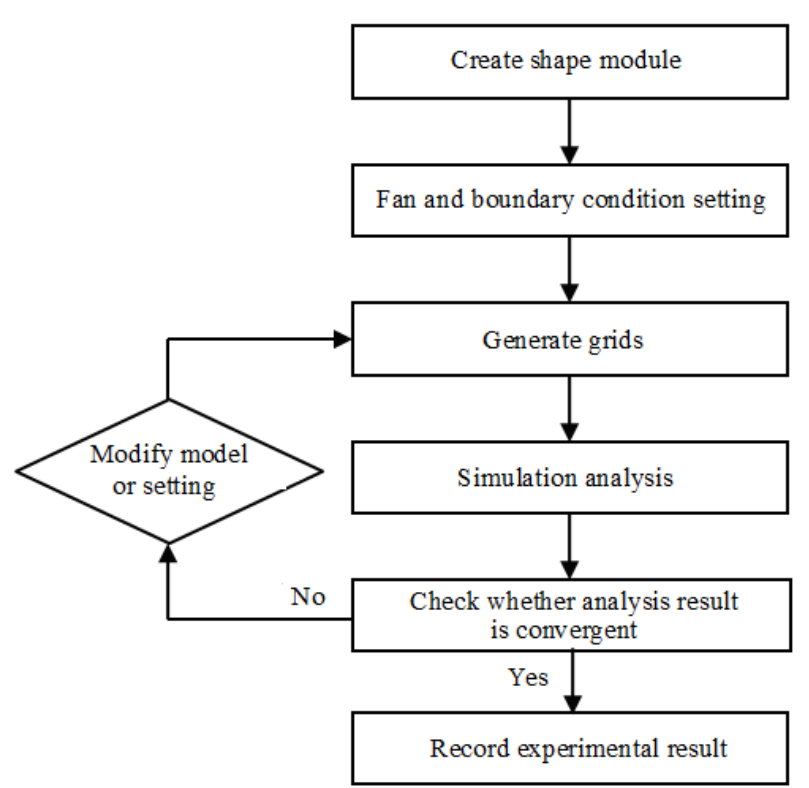

Figure 4. Simulation analysis flow chart

\subsubsection{Software simulated exterior and assembly setting}

The model is built according to the actual geometry and size of the analytic. The size of the simulated room is $4 \mathrm{~m} \times 4 \mathrm{~m} \times 3 \mathrm{~m}$, and Figure 5 shows the Ansys Icepak modeling. The calculation region is defined, in order to obtain accurate and rapid analysis results, the physical conditions of the problem and the complexity of the model are analyzed, and the required object and boundary condition setting are simplified or maintained, in order to build the model rapidly, and analyze the reasonable physical results. The number of grids of this house model is about 100 thousand, and the Ansys Icepak mesh generation is as shown in Figure 6. The number of grids can be reduced by simplifying the model and setting appropriate boundary conditions, in order to shorten the computing time and increase the efficiency of numerical analysis. The number of grids of mesh generation represents the accuracy of calculation, where smaller and more grids represent longer computing time, but the accuracy of the results is higher.

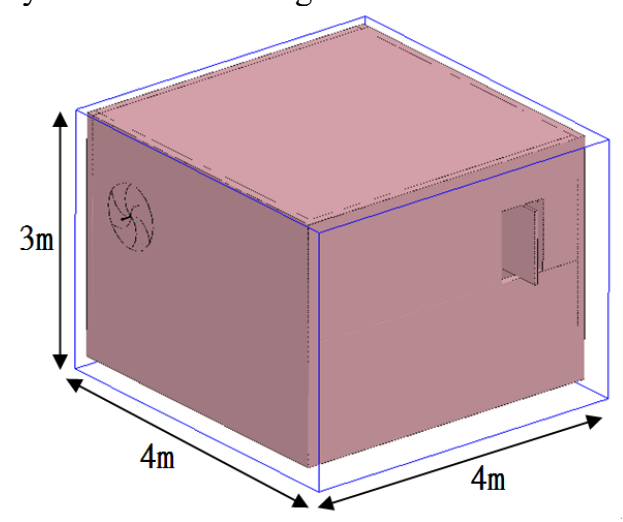

Figure 5. Ansys Icepak modeling

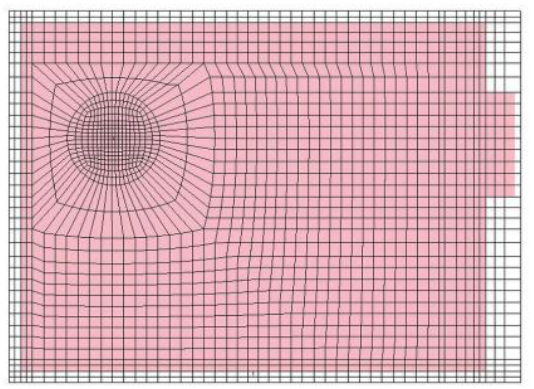

Figure 6. Front view of Ansys Icepak mesh generation

Finally, the heat source and ventilating fan are set up. The heat source simulates the human body in the room, the fan exhausts the excess heat from the room, and imports outside air to form convection. It is adjusted to the best convective section in order to observe whether the indoor air convection can effectively carry the excess heat away, and the effects of different angles on the temperature are discussed and recorded to determine the optimum conditions meeting indoor requirements, as shown in Figure 7.

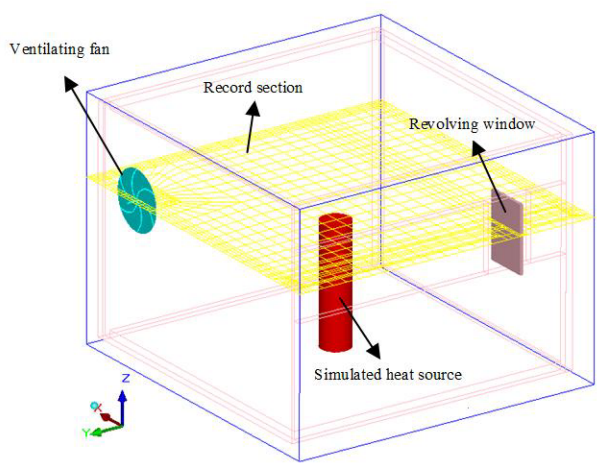

Figure 7. Icepak assembly setup diagram

\subsubsection{Software simulation analysis and calculation}

The analytic modeling and boundary condition settings are followed by computation. The solver plays the key role in numerical analysis, while the user evaluates the type of problem, and then selects the numerical calculation mode, which calculates the target value of convergence and the quantity of computer processor units, where the computer uses simple mathematical forms and mathematical equations for iterative computation, and the result is displayed by a convergence curve to check whether the target value of convergence is reached.

\section{Results and Discussion}

\subsection{Ventilation and air exchange of window at various openings}

This study uses Ansys Icepak software to simulate the interaction of a ventilating fan and a revolving window, and uses different angles of the revolving window to simulate the air flow and temperature distribution in the room. In the simulation of a ventilation system, the simulation data are compared with the 
thermal comfort of literature to determine the optimum inhabited environment.

\subsubsection{Simulated ventilation and air exchange of window at $90^{\circ}$ opening}

Figure 8 is the air flow vector diagram of a simulated revolving window at $90^{\circ}$. It is observed that a great deal of air is imported by the exhaust fan into the room. The maximum air velocity nearby the revolving window is $3.53011 \mathrm{~m} / \mathrm{s}$, the average air velocity in the room is $1.76506 \mathrm{~m} / \mathrm{s}$. As mentioned above, the comfortable temperature is $33.47{ }^{\circ} \mathrm{C}$ when the relative humidity is $50 \sim 80 \%$ and the air velocity is $2 \mathrm{~m} / \mathrm{s}$. According to the flow line vector arrowheads, the indoor air flow is helical, and a large volume of outside air rushes in the room. However, the number of vector lines leaving the exhaust fan is small, meaning the outside air is still flowing into the room, and the indoor air temperature is maintained at $24 \sim 25^{\circ} \mathrm{C}$.

Figure 9 shows the temperature profile of a revolving window at $90^{\circ}$, and a $30^{\circ} \mathrm{C}$ heat source is placed in the room. It is observed in the temperature profile that the temperature has not reached $30^{\circ} \mathrm{C}$. The heat is dissipated by this system, in order that the indoor space is kept comfortable without air conditioning.

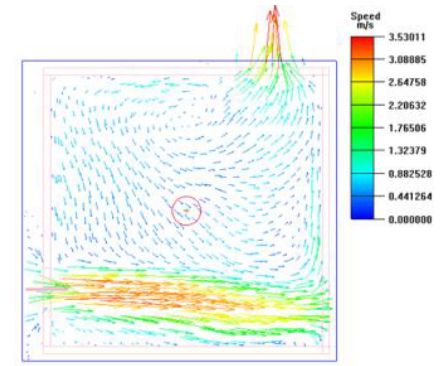

Figure 8. Top view of air flow vector of revolving window at $90^{\circ}$

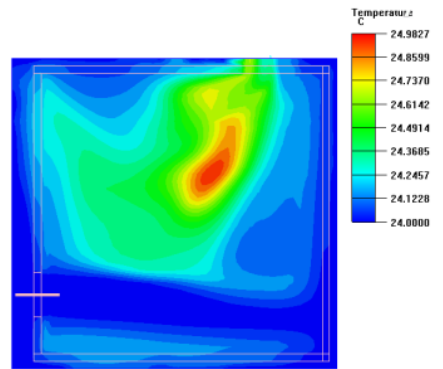

Figure 9. Top view of temperature distribution of revolving window at $90^{\circ}$

\subsubsection{Simulated ventilation and air exchange of window at $60^{\circ}$ opening}

Figure 10 shows the air flow vector of a simulated revolving window at $60^{\circ}$. It is observed that much outside air enters the room through the exhaust fan. The maximum air velocity nearby the $60^{\circ}$ revolving window is $3.29069 \mathrm{~m} / \mathrm{s}$, and the average air velocity in the room is $1.23401 \mathrm{~m} / \mathrm{s}$. The air flow imported through the window at $60^{\circ}$ opening must be lower than that through the window at $90^{\circ}$ opening. In order to enlarge the temperature range of this system, in the $60^{\circ}$ opening mode, when the indoor temperature is higher than $28^{\circ} \mathrm{C}$ and lower than $30^{\circ} \mathrm{C}$ (included), the air exchange is actuated. According to the vector arrowheads, the indoor air flow lines are also helical, as compared with the simulation of $90^{\circ}$ opening, the location collocation of the revolving window and ventilating fan has significant effect, and the circulating air maintains the indoor temperature at $24 \sim 25^{\circ} \mathrm{C}$, as shown in Figure 11 . A $30^{\circ} \mathrm{C}$ heat source is placed in the room, and the temperature profile shows the peak temperature is $27.66^{\circ} \mathrm{C}$, proving that this system can maintain the space at $26^{\circ} \mathrm{C}$ with a $30^{\circ} \mathrm{C}$ heat source.

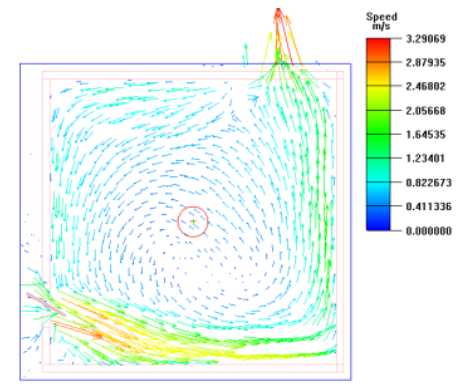

Figure 10. Top view of air flow vector of revolving window at $60^{\circ}$

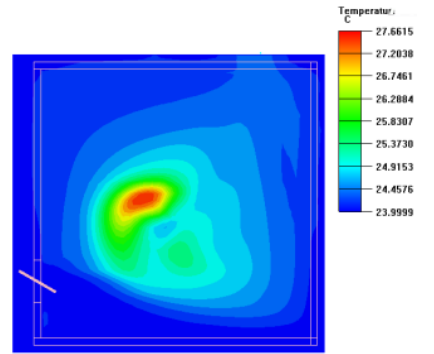

Figure 11. Top view of temperature distribution of revolving window at $60^{\circ}$

\subsubsection{Simulated ventilation and air exchange of window at $30^{\circ}$ opening}

Figure 12 shows the air flow vector of a simulated revolving window at $30^{\circ}$. The imported outside air flow is lower than the $60^{\circ}$ opening. However, in order to make this system applicable to different temperature ranges, this $30^{\circ}$ opening mode deals with the indoor space temperature condition above $26{ }^{\circ} \mathrm{C}$ and below $28{ }^{\circ} \mathrm{C}$ (included), the outside air is imported by the exhaust fan into the room, the maximum air velocity nearby the $30^{\circ}$ revolving window is $2.71231 \mathrm{~m} / \mathrm{s}$, the average air velocity in the room is $1.01712 \mathrm{~m} / \mathrm{s}$, the air flow input through the window at a $30^{\circ}$ opening is the lowest among the three modes of this system, and in the temperature range of $26^{\circ} \mathrm{C}$ to $28^{\circ} \mathrm{C}$, thus, provided there is a little ventilation and air exchange, a comfortable temperature can be maintained. According to the vector arrowheads, the indoor air flow lines are also helical. The circulating air spreads to all corners of the room, and the temperature is maintained at $24 \sim 25^{\circ} \mathrm{C}$, as shown in Figure 13 ; a $30^{\circ} \mathrm{C}$ heat source is placed in the room, the temperature profile shows the temperature is reduced to $28.64^{\circ} \mathrm{C}$, proving that when a $30{ }^{\circ} \mathrm{C}$ heat source equivalent to human body temperature is in this system, the body surface temperature can be reduced to $28^{\circ} \mathrm{C}$, and the indoor ambient temperature is maintained at $26^{\circ} \mathrm{C}$. 


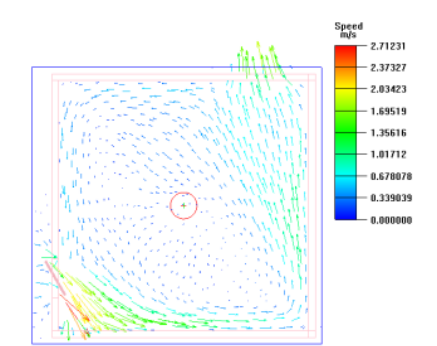

Figure 12. Top view of air flow vector of revolving window at $90^{\circ}$

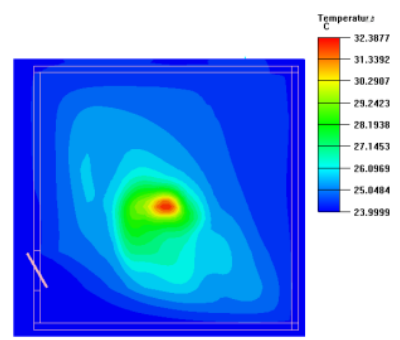

Figure 13. Top view of temperature distribution of revolving window at $90^{\circ}$

\subsection{Air Velocity and thermal comfort of revolving window in three modes}

In the simulation of three states of a revolving window, the indoor average air velocity is $1.0-1.8 \mathrm{~m} / \mathrm{s}$, as shown in Table 1. Taiwan is in an insular climate, the average humidity is mostly $50-80 \%$, as compared with literature, the comfortable temperature is $30^{\circ} \mathrm{C}$ when the relative humidity is $50 \sim 80 \%$ and the air velocity is $1 \mathrm{~m} / \mathrm{s}$; the comfortable temperature increases to $31^{\circ} \mathrm{C}$ when the air velocity is $1.5 \mathrm{~m} / \mathrm{s}$; and the comfortable temperature is as high as $33.47^{\circ} \mathrm{C}$ when the air velocity is $2 \mathrm{~m} / \mathrm{s}$. Table 1 shows that the difference between this ventilation system and the corresponding human thermal comfort is $6 \sim 7^{\circ} \mathrm{C}$. Therefore, provided the room is equipped with this system device, and provides air flow in the room, the human tolerable thermal comfort temperature can rise, and the service hours of air conditioning can be greatly reduced. According to "the air conditioning power consumption can be reduced by $6 \%$ as the air conditioning temperature is increased by $1{ }^{\circ} \mathrm{C} "$, this system uses air conditioning only if the indoor temperature exceeds $33.47{ }^{\circ} \mathrm{C}$, thus, the energy consumption is reduced by $36 \sim 42 \%$ for the temperature difference, which saves energy.

Table 1. Simulation data compilation of three modes

\begin{tabular}{|c|c|c|c|}
\hline Angle & $\begin{array}{c}\text { Average } \\
\text { indoor } \\
\text { temperature } \\
\left({ }^{\circ} \mathrm{C}\right)\end{array}$ & $\begin{array}{c}\text { Average } \\
\text { indoor air } \\
\text { velocity } \\
(\mathbf{~ m} / \mathbf{s})\end{array}$ & $\begin{array}{c}\text { Human } \\
\text { thermal } \\
\text { comfort } \\
\left({ }^{\circ} \mathrm{C}\right)\end{array}$ \\
\hline 30 & 24.8091 & 1.01712 & 30 \\
\hline 60 & 24.9153 & 1.23401 & 30 \\
\hline 90 & 24.3685 & 1.76506 & 31 \\
\hline
\end{tabular}

\section{Conclusion}

When the indoor temperature is $26 \sim 28{ }^{\circ} \mathrm{C}$, the ventilating fan is actuated, and the revolving window is opened to $30^{\circ}$. When the room temperature is $28 \sim 30^{\circ} \mathrm{C}$, the revolving window is opened to $60^{\circ}$. When the room temperature is higher than $30^{\circ} \mathrm{C}$, but below $33^{\circ} \mathrm{C}$, the revolving window is opened to the maximum $90^{\circ}$. The temperature range of this ventilation system is $26 \sim 33^{\circ} \mathrm{C}$, in this temperature interval, the indoor temperature can be effectively reduced to $24 \sim 25^{\circ} \mathrm{C}$. According to the statistical data of the Central Weather Bureau, the monthly mean temperature of July and August is 28 30 ${ }^{\circ} \mathrm{C}$ since 2011. Therefore, this ventilation system is sufficient for the various districts of Taiwan, the consumption of air conditioning can be greatly reduced, the spending rate of fossil fuel can be reduced, and civil diseases caused by long-term application of airconditioning systems can be relatively reduced. Future research of this system may determine the optimal position relation between the revolving window and ventilating fan, design more uniform air flow, and more significant cooling effects; moreover, as some fitments can be put in the simulation space to approximate the actual state, this ventilation system can be applied to the actual environment, and dwelling quality may be further improved.

\section{Acknowledgements}

This paper is the project NSC 102-2622-E-167-018-CC3 of Ministry of Science and Technology. Thanks to the Ministry of Science and Technology for supporting this project.

\section{References}

[1]R. J. de Deara, G. S. Bragerb, "Thermal confort in naturally ventilated buildings: revisions to ASHRAE standard 55," Energy and Buildings, Vol.34, pp.549$561,2002$.

[2]A.P. Gagge, J.A.J. Stolwijk, J.D. Hardy, "Comfort and thermal sensations and associated physiological responses various ambient temperatures, " Environmental Research, Vol.1, pp.1-20, 1967.

[3]H. Mayer, P. Höppe, "Thermal comfort of man in different urban environments," Theoretical and Applied Climatology, Vol.38, pp.43-49, 1987.

[4]S. Atthajariyakul, T. Leephakpreeda, "Real-time determination of optimal indoor-air condition for thermal comfort, air quality and efficient energy usage," Energy and Buildings, Vol.36, pp.720-733, 2004.

[5]C. L. Cheng, "Evaluating water conservation measures for Green Building in Taiwan" Building and Environment, Vol.38, pp.369-379, 2003.

[6]Guohui Gan, "Evaluation of room air distribution systems using computational fluid dynamics" Energy and Buildings, Vol.23, pp.83-93, 1995. 